\title{
EL COS AL TEATRE: EL RETORN DE L'ACTOR CORTESA
}

\author{
Jaume Melendres \\ (Institut del Teatre de Barcelona)
}

«L'actor no ha de fer servir el mocador a l'escenari; ni per a mocat-se ni per a escopir. En l'esfera del treball artístic, recordar les necessitats físiques és molt desagradable.»

Goethe

La història del cos pot ser excavada en molts Hocs diferents. Els més agraìts són els hospitals, les sales de tortura, els estadis i els camps de batalla o els de concentració, perquè permeten aplicar damunt l'objecte la lupa exasperada del cas extrem. Però tots aquests espais investiguen el cos al voltant de la idea de la mort. ${ }^{\prime} \mathrm{N}$ 'hi ha un, en canvi -que justament anomenem espai escènic-, on la investigació de la vida està Ilígada als cossos, i viceversa.

Atristòtil, el fundador de la reflexió dramàtica, no ho creia així, i afirmava $^{2}$ que la força de la tragèdia «existeix sense enfrontament en escena i sense actors». Tenia raó en la mesura que el dramatuxg s'ba de plantejar, i ha de resoldre, una sèrie de problemes que no són del regne corporal. Ara bé, a diferència del natrador $\mathrm{i}$ del poeta èpic (inventors l'un i l'altre de discursos que no necessiten mediacions corporals), i a diferència dels artistes plàstics (que van de la mobilitat a la immobilitat), els dramaturgs marxen pel camí que avança des de la idea fins al cos, creen xarxes de

1. Fins i tot els estadis. L'atleta de Marató tno és, per ventura, el símbol mateix de l'esportista que «arriba al final», que «ho dona tot a canvi de res»?

2. Poètica, 6. 
comportaments que necessiten, si volen assolit el seu sentit profund, la mediació d'uns professionals del cos. Del fet que el teatre vilu en l'obsessió del cos en són testimonis, per una banda, tots els attors que recorden amb pànic i emoció la primera vegada que van veure sortir de dins d'un cos les paraules que ells havien escrit al damunt d'un paper; i per altra banda, ens ho posa de manifest, com totes les toponímies, el mateix argot teatral, tan diferent dels argots cinematogràfics o televisius, dominats per l'obsessió tecnològica. Igual que els cossos, els escenaris tenen boca, espatlles i cametes, i fins i tot duen corbata; ${ }^{3}$ els actors es donen el peu $\mathrm{i}$, si són francesos i han entès el personatge, tenen «le rôle dans les jambes», perquè «fer bé» un personatge és -en datrer terme- caminar com ell; durant l'assaig, un substitut és una ombra —és a dir, la projecció d'un cos invisible- $i$, en qualsevol cas, un figurant destacat és una silueta, un cos retallat. Encara més: el teatre ha capgirat del tot el sentit de la paraula vedette (terme italià — vedetto- que significa «observatori», i que per extensió s'aplicava als sentinelles) fent que signifiqui «aquell que és vist» en comptes de designar «aquell que veu», i l'acaba transformant en la paraula més reveladora $\mathrm{i}$ alhora més odiosa del vocabulari teatral: star. Un terme que Hollywood ha divulgat però que neix als escenatis.

I és precisament un home de teatre, Ëmile Zola - l'autor d'El naturalisme al teatre-, qui millor explica el significat d'aquest concepte. Curiosament, no ho fa en un text teodric, sinó en una novella: Nana. Just abans d'estrenar-se La Venus rossa (musical eròtico-mitològic), Bordenave, l'empresari del local, parla amb uns coneguts sobre Nana, l'actriu debutant. "M'han dit -comenta un interlocutor-- que Nana té una veu deliciosa.» "I que és molt bona actriu», afegeix un altre. La resposta de Bordenave els deixa perplexos. Nana, diu l'empresari, canta com una «vraie seringue» (una regadora, podríem dir) $i$, com a intèrpret, no sap on posar ni els peus ni les mans. Petò tot i així, Nana - prediu el direc. tor-empresari- triomfarà perquè «té una altra cosa que val per tot, $\mathrm{i}$ quan es té això no cal res més». La pell, opina Bordenave. Però Zola ens explica una altra història: Nana electritza els espectadors (masculins i femenins) de $\mathrm{La}$ Vents rossa perquè apareix damunt l'escenari com un cos nou, un cos diferent: es mou, somriu i mira d'una altra manera. Nana, segons les notes prèvies de Zola, és una nova síntesi de les dues ces: la ce de cel i la ce de cul. Una nova imatge del conflicte secular entre l'àngel $i$ el dimoni. Nana triomfa, malgrat els galls que deixa anar, perquè ens

3. La boca, dbviament, és l'obertura de l'escenari; les espatlles són els espais laterals de I'escenari, que el públic no ven; les cametes, els plafons de roba o de paper que priven que les espatifles aforin; la corbata és la part de l'escenati més pròxima a l'espectador, també visible quan el tel 6 és tancat. 
proposa un nou ús del cos al servei d'unes noves idees sobre el cos. Com Sarah Bernhardt, Marylin Monroe, Sofia Loren o Gérard Philippe. Nana, com tots els noms que han nascut després, és una stor, un cos emissor de llum sota la llum.

Siguin quins siguin els mecanismes de producció de stars, fóra pura banalitat creure que aquests «mites» són el resultat d'una prostitució di. recta o de la manipulació interessada d'un cos per part d'un cervell astut. Aquest univers que anomenem «el món de l'espectacle» és, en efecte, l'àmbit de molts negocis bruts, de molts xantatges i de moltes humilia cions, però també és el lloc on les idees sobre el món fan tractes amb els cossos, on es fecunden mútuament per tal de creat noves figures que són, alhora, figures de comportanent i figures de pensament. Explicats per Jean Duvignaud, ${ }^{4}$ els amors tanosos entre La Champmeslé i Racine (segle xvrr) deixen de ser la història banal de l'actriu que triomfa «perquè es liga lautor de moda», o la història del dramaturg que «s'aprofita de l'actriu i li promet grans papers a canvi de serveis adultetins», $i$ apareixen com l'exemple concret d'un fet molt més general. En abraçar la Champmeslé - diu Duvignaud- «Racine no sols abraça un cos de dona desitjable: abraça alhora un món de valors expressables, un conjunt de signes, un estil de representació, una presència carnal i social». L'actriu $i$ el dramaturg es potencien l'un a l'altre: «La reciptocitat de les emocions que la parella es suscitava mútuament permet al poeta inventar o fxar conductes fins aleshores eventuals o simplement pressentides.» EI teatre, diu Duvignaud, neix del contacte entre un cos i una idea.

Aquest contacte no és pas fàcil. El teatre sempre s'ha proposat expressar a través dels cossos alguna cosa que no és estrictament corporal i per això la seva històtia oscilla entre dos extrems: el de la simulació i el de la «mostració». Altrament dit, per tal d'explicar allò que hi ha darrera d'un cos, cal ensenyar-lo o no? ¿Cal parlar de la realitat per parlar de la veritat? $O$ bé cal emmascarar.lap I si admetem que sí, ¿de quina manera $i$ en quin grau?

Les respostes a aquestes qüestions han variat al llarg dels segles, però convé recordar que la tradició dramàtica occidental arrenca d'un sistema de representació, tècnic i filosòfic, que resol la disjuntiva apostant a favor de la dissimulació. La teoria tràgica es basa en la idea que el personatge no ha de tenir cap relació amb el cos que hi ha a sota. El cos i els sentiments de l'actor no són, no han de ser, ni el cos ni els sentiments del personatge perquè l'actor és el simple suport físic d'unes tensions i d'unes emocions que ni li pertanyen ni l'afecten. L'actor grec només «porta el

4. L'acteur. Esquisse d'une sociologie du comédien, Gallimard, 1965. 
gegant». La màscara, l'onkos i els coturns el dissimulen, l'emmascaren totalment. A Grècia hi ha persones que viuen del teatre però no hí ha, en el sentit modern de la paraula, actors.

Caldrà esperar uns quants segles - vint, exactament - per tornar a trobar, en els manifestos expressionistes, aquesta reivindicació de l'emmascarament. Gordon Craig la renovarà en afirmar ${ }^{5}$ que «l'actor actual hautia de desaparèixer si volem fer obra d'art» perquè la seva cara no fa altra cosa que imitar amb ganyotes ridícules els rostres humans, i vaticinarà la necessària transformació de l'actor convencional en una supermarioneta. Hi ha, doncs, un fil invisible que lliga Aristòtil i Craig, i aquest fil és el convenciment que el personatge teatral és una entitat que procedeix de l'estilització física i espiritual de l'individu. L'espectador s'hi reconeix no pas perquè sigui la concreció lluminosa, l'star, d'un desig o d'una imatge, sinó perquè resumeix, en una síntesi que només pot ser de l'ordre de l'art, l'amarga experiència d'un individu -l'actor- que també és víctima del drama collectiu.

Però entre Aristòtil i Craig hi ha hagut molts altres punts de vista, $\mathrm{i}$ han estat aplicats. La commedia dell'arte, en un genial i irrepetible compromís, fa el primer pas en el sentit contrari: manté la màscara però, alhora, converteix el còmic en un virtuós del cos, en algú que, sense donar la cara, es revela davant l'espectador conn un artesà especial - l'artesà que es treballa a si mateix - gràcies a un ofici que és el resultat d'un llarg aprenentatge. 6

Si això no fos simplificar massa un procés que es perd a cada instant en les ziga-zagues de la seva complexitat, podríem dir que durant molts segles la història de l'actor és la d'un progressiu despullament de tots els artificis que dissimulen el seu cos. El punt culminant d'aquest itinerari és el segle xvrr francès, el segle de Racine, de Corneille. En aquest segle, el cos de l'actor $\mathrm{i}$ el cos def personatge assoleixen la mínima distància possible, física i conceptual. El públic -em refereixo al públic noble-m ha envä̈t l'escenari fins al punt que l'actor ja ni tan sols té lloc per a moure els braços. ${ }^{7}$ I el personatge, a més a més, sigui romà, francès o grec, es vesteix igual que el públic. Caldrà esperar tres segles més per tornar a trobar una promiscuïtat, entre l'art i la vida, similar.

Una promiscuïtat insostenible perquè significa la mort de l'art dramàtic. Petò desfer-la no era fàcil. Les temptatives d'actors com Taltna o La

5. De l'art del teatre, recull de textos publicat l'any 1911.

6. Justament, «commedia dell'arte» no significa «comèdia de l'art», com se sol creure, sinó «comèdia de l'ofici».

7. D'aquí ve tota la tradició de la interpretació encatcarada, basada en l'elocució i en l'expressivitat exacerbada dels ulls que tendeixen a sortir de les òbites. 
Clairon topen amb obstacles que són alhora d'ordre ideològic i d'ordre eco. nòmic. ${ }^{8}$ Malgrat tot, lentament es va imposant, al llarg del segle xvirr, la idea de la naturalitat, una idea que s'obre camí des de Diderot fins a Stanislavski. Paradoxalment, aquesta idea de la naturalitat tornarà a establir les antigues fronteres entre l'art i la vida. Des d'ara, el personatge no es disfressarà per tal de dissimular el cos, sinó per tal de mostrar-lo produint illusió de realitat. L'actor francès es vestirà de persona romana, i l'espectador serà expulsat altre cop dels escenaris perquè la mentida sobre la realitat exigeix la distància.

Però la gran aportació del llarg corrent naturalista tau en el fet que, a partir d'aquest moment, fer un personatge ja no setà interpretar-lo, sinó que setà encarnar-lo. L'actor assolirà el seu màxim estatut de prostituta en la mesura que farà el que calgui perquè el personatge s'apoderi d'ell, íntimament. «La naixença del personatge - dirà Stanislavski- és un procés natural, semblant a la naixença d'un ésser humà.» I de la mateixa maneta que una mare alleta el fill, l'intèrpret nodrità el seu personatge amb les seves vivències personals, recorrent al dispòsit de la seva "memòria afectiva», lifurant-li sensacions, records $\mathrm{i}$ sentiments, inventant per a ell un passat i un futur que van molt més enllà de l'abans i del després de l'obra, suplint les lacunes biogràffques que són imputables a l'autor: l'actor ha de dir el text per posar de manifest el subtext, tot allò que l'autor s'ha deixat al tinter perquè no pot ser expressat a través de les paraules. Amb Stanislavski, la investigació escènica dels cossos coincideix, en alguns aspectes, amb la investigació psicoanalítica que li és contemporània perquè apella a l'inconscient -i vol descobrir-lo- i perquè diu, com Freud, que el silenci i el lapsus són més significatius que qualsevol paraula. ${ }^{9}$ I amb Stanisłavski apareix, consegüentment, una tècnica de treball d'actor fins aleshores inèdita, la improvisació, gràcies a la qual l'actor, en comptes de buscar tons i entonacions correctes per a un text prèviament memoritzat, es deixa dur —una mica com el pacient al sofà del psicoanalista- pel misteri de les associacions psicosomàtiques.

Però, malgrat tot, aquesta associació profunda entre l'actor i el perso-

8. G. Baty i R. Chavance, a l'art théâtrale, narren l'èxit de La Clairon (17231803) representant cl paper de Roxara, a Botdeus, un dia que el vestuari no havia arribat a temps i es va veure obligada a actuar ensenyant els braços. Quan li van preguntar per què no tornava a repetir l'experiència, va respondre: "No veı que m'arruinaré? [...] Hauria de refer tot el meu vestuari.» I certament, en una època en què cada actor finançava cls seus vestits, qualsevol canvi era una càrrega sovint impossible d'assumir.

9. Això no significa que Stanislavski fos freudià; fans i tot s'ignota si va arribar a conèixer les seves teoties. Més aviat, en el treball concret amb els actors, recorria a tècniques conductivistes. 
natge té com a objectiu l'expressió de l'altre. D'aquí ve, en gran part, la immensa seducció que aquest tipus d'actor exerceix damunt nostre. És el nostre enviat a una aventura que nosaltres no podena o no gosem viure, l'aventura del canvi d'identitat i de cos, l'aventura de l'alienació. Ells - perquè són «exhibicionistes», o perquè algú els paga perquè ho siguin?-, ells són sempre al vestíbul de la bogeria, amb l'única diferència enfront dels alienats veritables que ells, els comics, posseeixen el secret del retorn, prenen la precaució de deixar teta seu, com els nens del conte, les molles de pa que els permetran tornar al propi cos un cop acabada la funció, a altes hores de la nit, en comptes de quedar-se, en la fixació irreversible del Napoleó de manicomi, al cos i al caràcter del personatge visitat. I d'aquí ve també eí refús o el fàstic que ens provoquen: a la pell els queden les marques de tots els maquillatges, el $\cos -$ de vegades - no torna a ser ben bé com era (Jack Nicholson, per exemple, ja no tornarà a ser prim com abans; Lawrence Olivier modificarì la seva veu per sempre perquè vol interpretar (tello) $i$, en tot cas, sabem que aquest trànsit constant no sols d'un $\cos$ a un altre $\cos$, no sols d'un cos d'un temps a un $\cos$ d'un altre temps, sinó també, sovint, del cos d'un sexe al cos d'un altre sexe, pot crear un hàbit perillós que nosaltres, per rentar-nos les mans, atribuïm a la seva perversitat moral (el món de l'espectacle «és ple de putes i de maricons») en comptes d'atribuir-lo a la profunda perversitat filosòfica d'aquesta feina que fan per al nostre plaer. ${ }^{10}$

Aquesta assimilació d'actrius i d'actors a prostitutes i homosexuals no la trobem només en boca de la gent del carter, no és només un tòpic d'ignorants o d'envejosos. La trobem també en els mateixos professionals, i pot ser expressada d'una manera encara més crua. És un home de teatre, Jerzy Grotowski, qui ha fet, en nom d'una altra idea del teatre, les acusacions més dures a aquests intèrprets que ell, sense metàfora, qualificava d'«actors cortesans», dels quals veu «la seva misèria, el seu mercantilisme, aquest mercat d'un organisme humà martiritzat pels seus protectors: director d'escena, empresari, etc.». Aleshores, afegeix, «l'art de l'actor es troba infinita. ment a prop de la prostitució». Enfront d'aquest actot cortesà que sol treballar per a un «director-macarra», Grotowski reivindica l'actor sant, i la diferència l'explica així: "... És pràcticament la mateixa que separa la saviesa de la tamera dels gests de iliurament i d'acceptació que sorgeixen de la dona enamorada.»"1

10. La ja esmentada Champmeslé va expressat millor que ningú aquesta perversitat filosòffa, aquesta voracitat, en demanar a Racine «un paper que pogués expressar totes les passions».

11. Jerzy Grotowski, Cap a un teatre pobre. 
Deixant de banda la seva sorprenent virulència expressiva, la seva misogínia escandalosa, Grotowski, amb els seus treballs teòrics i pràctics, formula el canvi més radical sobre les concepcions del cos al teatre que s'ha produit aquest segle. Aquest trencament no és el resultat d'unes experiències aillades, de laboratori, d'unes manies personals o d'un misticisme delirant. Grotowski, en realitat, no fa altra cosa que dur a l'extrem unes idees que desborden el camp del teatre i connecten, amb una precisió gairebé matemàtica, amb una nova filosofia de la vida i del cos que s'està escampant simultàniament per Europa $\mathrm{i}$ pels Estats Units. La mateixa sexualització del llenguatge usat per Grotowski correspon, fil per randa, a la sexualització creixent del llenguatge de les generacions joves dels anys seixanta. I «l'actor que s'ha de lliurar totalment», que «s'ha de lliurar nu», en «la intimitat més fonda, confiadament, com ens lliurem a l'amor», fins al punt «d'autopenetrar-se», correspon, com una imatge a una altra imatge, al desig cada vegada més generalitzat entre aquelles generacions d'abandonar la idea de «fer carrera» per a dedicar-se a unes professions, a unes activitats o a unes formes de vida que els permetin expressar-se personalment. Aquest és l'ideal grotowskià i l'ideal de l'època: l'autenticitat i la seva germana teatral -l'espontaneïtat - són les paraules clau. I és aquesta mateixa autenticitat que empeny el jove a renunciar al personatge que li estava destinat, la que empeny l'actor a renunciar als personatges. De vegades partirà del text d'un personatge, però ni l'encarnatà ni el representarà, sinó que es manifestarà íntimament davant un espectador, probablement minoritati, portat també per una «autèntica necessitat espititual» a viure el procés infinit de la seva (ptòpia) creació. ${ }^{2}$

Certament, als escenaris de tot el món encara es continua fent el vell teatre, el teatre dels actors cortesans, petò qui marca les noves pautes de la pràctica teatral i les difon, encara que sigui en circuits limitats, és Grotowski $\mathrm{i}$, amb ell, una sèrie de grups -el Living Theatre serà el més famós- que propugnen alhora una nova forma de viure $i$ una nova forma de fer teatre, que s'acosten infinitament a aquesta abolició de les fronteres entre l'art i la vida que va ser el happening, on l'actor desapareix com a tal $\mathrm{i}$ assoleix la condició suprema del simple provocador. El teatre, més que mai, serà el mirall collocat damunt la vida o, si més no, d'una vida alternativa.

Però avui, contra pronòstic - perquè aquell pas semblava irreversible--, assistim arreu del món al retorn del gran teatre de repertori, que és també el teatre dels grans personatges. ${ }^{13}$ Aquells mateixos actors $i$ directors que

12. Op. cit.

13. El teatre produït a Catalunya en els cinc darrers anys ens ofereix nombroses 
un dia van ser «sants», s'han tornat "cortesans» $i$ es comporten com a tals a dalt $\mathrm{i}$ a baix dels escenaris, és a dir, aspiren a interpretar els màxims papers $\mathrm{i}$ a guanyar el màxim de diners. Cobrar més que els altres -en funció de la llargada del paper o de la pròpia cotització- sembla legítim altre cop, després de molts anys de reivindicar la igualtat.

Aquest fenomen, alhora estètic i laboral, pot ser interpretat de moltes maneres. El podem atribuir - una vegada més- a la perversió moral d'uns professionals abdicacionistes, a la crisi econòmica o a la crisi generalitzada de valors.

En qualsevol cas, és el tesultat del fet que s'ha clausurat una època que creia possible la tevolució de l'esperit i assajava la del cos, una època que s'havia anat despullant de totes les limitacions externes, de tots els tabús: del matrimoni que transforma la persona en una nova edició del personatge del matit o de la muller, en algú que té un sol paper escrit i ben escrit; o dels vestits que només servien per a aparentar, de les corbates i americanes pròpies dels executius, o dels sostenidors constrenyidors o de tota aquella faramalla de vestits femenins que duien, justament, el nom de l'escena per a la qual havien de servir - coktail, esport, soirée.

El retorn d'aquest vestuari és parallel al retorn del personatge teatral i al retorn de l'actor cortesà, l'únic actor que, en la mitja ficció dels seus viatges a l'altre ens recorda tots aquells que no serem perquè només som capaços de ser el que som. Avui, que tornem a dir frases que semblaven per sempre bandejades, frases com «aquell amic meu s'ha convertit en tot un personatge», Peer Gynt, que fou capaç de ser-ho quasi tot, ens torna a seduir.

illustracions d'aquest canvi de tendència. Els grans èxits corresponen a títols com Hamlet, Terra baixa o Peer Gynt. Fins i tot Albert Boadella, que sempre havia ignorat amb un menyspreu deliberat la història del teatre, s'interessa -sense renunciar del tot, és ciar, al seu estil- per un deis grans personatges del teatre universal, Ubú.

Però l'exemple més clar ens l'ofereix el Marat-Sade que Pere Planella dirigeix al Romea l'any 1982. Aquest text havia causat arreu del món un gran impacte quan a finals dels seixanta o a principis dels setanta havia estat estrenat, entre altres coses $\multimap$ sobretot- perquè era la primera vegacta que es veia a dalt de l'escenari allò que ja aleshores s'anomenava expressió corporal, tan lligada als pressuposits grotowskians. La indiferència amb què va ser acolliđ̆a aquesta nova versió és, en si mateixa, ben reveladora d'un canvi radical de valors, però encara ho és més el fet que Planella, precisament l'introductor de Grotowski a Catalunya, busqués l'espectaculatitat del muntatge en la utilització del vídeo més que no pas (com en les versions anteriors) en la brutalitat d'uns cossos en el paroxisme de la pesta artaudiana, més en el diferit que no pas en la força de les imatges vives. 